\title{
Rheological consideration in fracture of wood in lateral tension
}

\author{
Yuka Miyoshi $^{1} \cdot$ Yuzo Furuta ${ }^{1}$
}

Received: 8 October 2015/Accepted: 7 January 2016/Published online: 9 February 2016

(C) The Japan Wood Research Society 2016

\begin{abstract}
For the purpose of elucidating the effect of rheological property of wood on lateral tensile fracture, failure strain, elastic modulus, and creep at various temperature conditions were measured. And, relationship between the degree of softening or fluidity and lateral tensile failure strain was examined. To discuss the fracture mechanism from the results of the failure strains, broken specimens were observed and each appearance ratio of fractures in different tissue was calculated. The results obtained are as follows: (1) Failure strains were reduced in the temperature from 80 to $95^{\circ} \mathrm{C}$, because the weakest parts as a starting point of fracture changed in all of the specimens and the weakest parts for fractures were increased with temperature rise. (2) The effects of softening of wood are important for increasing failure strains up to the temperature range in which the fracture mechanism changes. (3) Creep deformation, that is, fluidity was included in the wood deformation process, and the fluidity had different characteristics dependent on the anatomical characteristics. It also became clear that the creep deformation measured in the load range of this study did not affect the increase in failure strain significantly.
\end{abstract}

Keywords Rheology · Failure strain · Elastic compliance $\cdot$ Creep compliance $\cdot$ Fracture surface

Yuzo Furuta

furuta@kpu.ac.jp

1 Division of Environmental Sciences, Graduate School of Life and Environmental Sciences, Kyoto Prefectural University, Hangi-cho, Shimogamo, Sakyo-ku, Kyoto 606-8522, Japan

\section{Introduction}

The effects of tensile direction to annual rings, moisture and temperature conditions, tree species and histories of drying or heating on lateral tensile deformation characteristics of the wood were examined for the purpose of elucidating the mechanism of the lateral tensile deformation of wood previously [1-3]. The results of their examination indicated that the failure strain of wood increased under the influence of its softening through moisture and heat effects. Then, it was thought that rheological properties were contributable to fracture.

On the other hand, some previous studies of failure strain of wood have been reported, such as the relationship between structural factors such as the lignin content or the crystallinity of wood and failure strains [4-7], the relationship between the strain distribution in the specimen and the fracture surface [8], and the relationship between failure strains and factors such as the moisture content and temperature [9-11]. There is a mathematical modeling study related to the time dependent of creep behavior of wood [12], however, the study of evaluating rheological properties of wood both qualitatively and quantitatively and refer to the relationship between fracture and rheological properties have not been found. If the relationship between rheological properties of wood and its fracture could be clarified, it will be possible to determine a softened state required for the processing and indicate the optimum moisture and temperature conditions. Therefore, it is significant to elucidate the relationship between fractures and rheological properties of wood, which has not been discussed yet, in terms of both studies on wood properties and the development of control technologies for wood. 
In this study, therefore, failure strain, elastic modulus, and creep at various temperature conditions were measured. And, relationship between the degree of softening or fluidity and lateral tensile failure strain was examined. To discuss the fracture mechanism from the results of the failure strains, fracture surface was observed and appearance ratio of fractures was calculated.

\section{Materials and methods}

\section{Materials}

The specimens were determined to be of Hinoki (Chamaecyparis obtusa Endl.). The block-shaped specimens with the annual ring inclinations of $0^{\circ}$ (tangential direction), $45^{\circ}$ (angle between tangential and radial direction), and $90^{\circ}$ (radial direction) against the tensile direction were collected from the sapwood part. Thin cross-sectional specimens with the thickness of about $0.1 \mathrm{~mm}$ (longitudinal direction) and with the dimensions of $3.4 \mathrm{~mm}$ in width $\times 20 \mathrm{~mm}$ in length were used for the tensile breaking test. This shape of specimen was selected because the most reliable results were obtained within the load range of the test device in pretest and the origin of the fracture could be clearly observed at cellular level. Furthermore, the thin specimens were prepared with extreme care not to generate scratches or knife marks which could be the origin of fracture. For the creep test, specimens in the same shape as that for the tensile breaking test were used.

Cross-sectional specimens with the thickness of about $1.6 \mathrm{~mm}$ (longitudinal direction) and with the dimension of about $3.6 \mathrm{~mm}$ in width and $20 \mathrm{~mm}$ in length were used for measuring the elastic modulus. This shape was decided because providing repeated load may cause fatigue fracture in the measurement of elastic modulus. Therefore, specimens were made in the maximum shape that could be nipped by chuck, and were cut from the block-shaped specimen using a circular saw. Similarly to the tensile breaking test, specimens were prepared with the annual ring inclinations of $0^{\circ}$ (tangential direction), $45^{\circ}$ (angle between tangential and radial direction), and $90^{\circ}$ (radial direction) against the tensile direction in the measurement of elastic modulus. Furuta et al. [13-15] reported that the values of elastic moduli vary sensitively under the influence of drying and heat history given to the specimens before the measurement. To unify the histories of specimens, they were cooled down to $1{ }^{\circ} \mathrm{C}$ at $1{ }^{\circ} \mathrm{C} / \mathrm{min}$ after boiled and measured in waterswollen state.

\section{Tensile breaking test}

A thermo-mechanical analyzer (manufactured by Seiko Instruments Co., Ltd.; TMA/SS6100) was used in the measurement. All of the measurements were carried out in water kept at the constant temperature, and the temperatures were $5,20,40,60,80$, and $95^{\circ} \mathrm{C}$. The distance between chucks was set to $10 \mathrm{~mm}$, and the specimens were measured with the load of $1 \mathrm{~N} / \mathrm{min}$ until they were fractured. The measurement results were adopted only for the specimens fractured roughly at their central portion, and the specimens had exceptional deformation behaviors were excluded. The number of specimens in the results was adopted 5-8 pieces per condition.

\section{Creep test}

Creep test was carried out with the same device and in the same temperature conditions. The specimens were attached with the same state as those in the tensile breaking test. The creep load was determined to be $25 \%$ of the strength obtained in the tensile breaking test in each temperature condition. At $30 \mathrm{~s}$ after the load was reached at creep load, the creep amount was calculated as the creep compliance $(J(30))$. The average value of 3-5 specimens per condition was used as the results, except extremely large or small results caused by the slip of the specimens at the chuck site or the distortion of their mounting.

\section{Measurement of elastic modulus}

Elastic modulus was measured by applying load half as large as the creep load in each temperature repeatedly. The following load rates were adopted; $1 \mathrm{~N} / \mathrm{min}$ which was the same loading rate in the tensile breaking test and $9.8 \times 10^{6}$ $\mathrm{N} / \mathrm{min}$ which was the maximum loading rate controlled by the device. In this study, the elastic modulus obtained by measuring load rate of $1 \mathrm{~N} / \mathrm{min}$ is defined as the elastic modulus $(E)$ and the elastic modulus obtained by measuring load rate of $9.8 \times 10^{6} \mathrm{~N} / \mathrm{min}$ is defined as the instantaneous elastic modulus (IE). For the purpose of unifying the histories of the specimens, as described in "Materials", the specimens were held at about $100{ }^{\circ} \mathrm{C}$ for about $5 \mathrm{~min}$, then cooled down to $1{ }^{\circ} \mathrm{C}$ at $1{ }^{\circ} \mathrm{C} / \mathrm{min}$, heated up again to about $100{ }^{\circ} \mathrm{C}$ at the temperature rising ratio of $2{ }^{\circ} \mathrm{C} / \mathrm{min}$, and furthermore cooled down to $1{ }^{\circ} \mathrm{C}$ at $1{ }^{\circ} \mathrm{C} / \mathrm{min}$ and raised again to around $100{ }^{\circ} \mathrm{C}$ at the temperature rising ratio of $2{ }^{\circ} \mathrm{C} / \mathrm{min}$ prior to the measurements. The measurements were performed during the heating process. The IE was measured in the first heating process and $E$ was measured in the second heating process, respectively. 


\section{Observation of fracture surface}

Fracture surfaces of the specimens that were fractured under the tensile breaking test were observed with an electron microscope [TM3030Plus (Bruker AXS Co. Ltd)]. The appearance ratios of fracture surfaces were observed in five specimens showing typical fracture surfaces. The appearance ratios were obtained from the percentage of the projected length of the fracture along the annual ring boundary and the ray tissue in the tensile direction. The definition of the projected length of the fracture is illustrated in Fig. 1, using the photograph of the fracture surface of the specimen with the annual ring inclination of $90^{\circ}$. The fractures were observed along the ray tissues arranged parallel to the tensile direction in the specimens with the inclination of $90^{\circ}$. These fracture surfaces could be observed prominently only for the specimens with the inclination of $90^{\circ}$. With regard to the specimens with the inclination of $90^{\circ}$, therefore, breaking length which was judged to be along the ray tissues and was fractured linearly over four cells were also measured. Then, the percentage of the breaking length of ray tissue in horizontal direction was measured when the breaking length measured at $20{ }^{\circ} \mathrm{C}$ was defined as $100 \%$.

\section{Results and discussion}

\section{Effects of the temperature on the fracture}

The relationship between the failure strain and the temperature is shown in Fig. 2. Significant differences in failure strains between the specimens with the annual ring inclination of $0^{\circ}$ and $90^{\circ}$ were not found, and failure strains

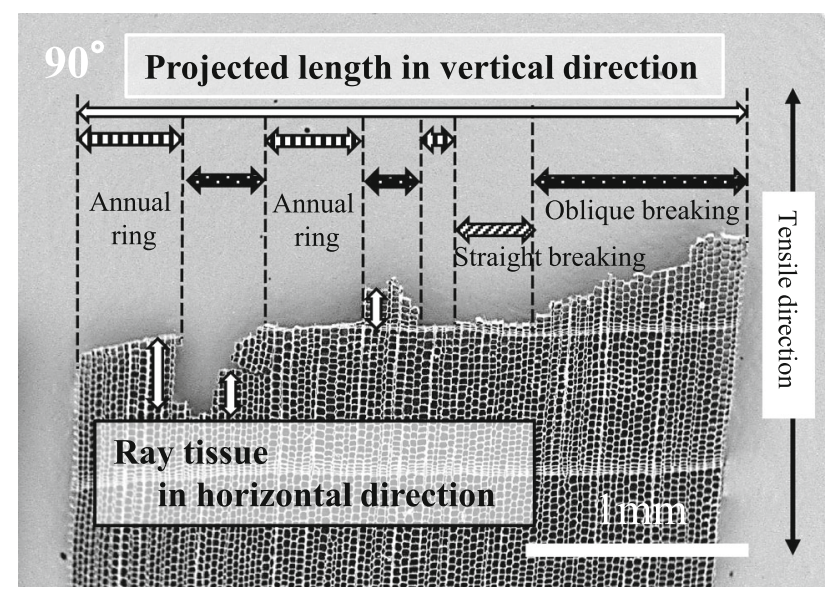

Fig. 1 An example of photograph used for calculating appearance ratios of fractures along each tissue. From these photographs, projected lengths of fracture surfaces along each tissue and ray tissues in horizontal direction were measured and calculated were tended to increase from about 3-6\% with increase in temperature. On the other hand, in the specimens with the annual ring inclination of $45^{\circ}$, failure strains were larger than those with the inclination of $0^{\circ}$ and $90^{\circ}$. And, failure strain increased with increase in temperature, but the failure strains at $95{ }^{\circ} \mathrm{C}$ were reduced to the same extent as the result at $5{ }^{\circ} \mathrm{C}$. Comparing the relative failure strains in Fig. 2, in the specimens with the annual ring inclination of $0^{\circ}$, relative failure strains increased largely with increase in temperature. In addition, decrease in failure strain at $95{ }^{\circ} \mathrm{C}$ was observed in all the specimens regardless of their annual ring inclination, and the decrease was the largest for the specimens with the annual ring inclination of $45^{\circ}$.

As a reason for the decreasing of failure strain, the fracture mechanism was considered to be different between 80 and $95^{\circ} \mathrm{C}$. In water-swollen wood, fracture in the intercellular layers is easy to occur at high temperature [16, 17]. Thus, fracture surface was observed to discuss the fracture mechanism.

The appearance ratios of various fractures and photographs of broken specimen with the annual ring inclination of $0^{\circ}$ are shown in Fig. 3. The photographs show that the fractures tended to occur in the intercellular layers along the ray tissues even at any temperature. The appearance ratio of fractures along the ray tissues was also as high as about $60-70 \%$ at 20 and $80{ }^{\circ} \mathrm{C}$. Such a fracture tendency appeared at $95^{\circ} \mathrm{C}$ pronouncedly, where the appearance ratio of fractures along the ray tissues was $90 \%$. From these results, fractures in the intercellular layers along the ray tissue tended to occur in the specimens with the annual ring inclination of $0^{\circ}$ in the temperature range up to $80^{\circ} \mathrm{C}$. On the other hand, intercellular layers along the ray tissues became weak in the higher temperature range, therefore, the factures along the ray tissues increased and failure strains decreased as shown in Fig. 2.

The appearance ratios of various fractures and photographs of broken specimen with the annual ring inclination of $45^{\circ}$ are shown in Fig. 4. The photographs show that fractures tended to occur in the intercellular layers along the ray tissues for the specimens with the inclination of $45^{\circ}$. Focusing on the appearance ratios of fractures, the ratio along the ray tissues was almost equal at 20 and $80{ }^{\circ} \mathrm{C}$. For the specimens at the $95^{\circ} \mathrm{C}$, however, the appearance ratio of fractures along the ray tissues decreased and the fractures along the annual rings were observed, and the tendency was not found up to $80^{\circ} \mathrm{C}$. From these results, the fractures tend to occur in the intercellular layers along the ray tissues in the temperature range of up to $80{ }^{\circ} \mathrm{C}$. Whereas the intercellular layers between early wood and late wood were also considered to become weak part which was easy to be fractured in addition to the intercellular layers along the ray tissues in the temperature range above $80{ }^{\circ} \mathrm{C}$. In other words, the 

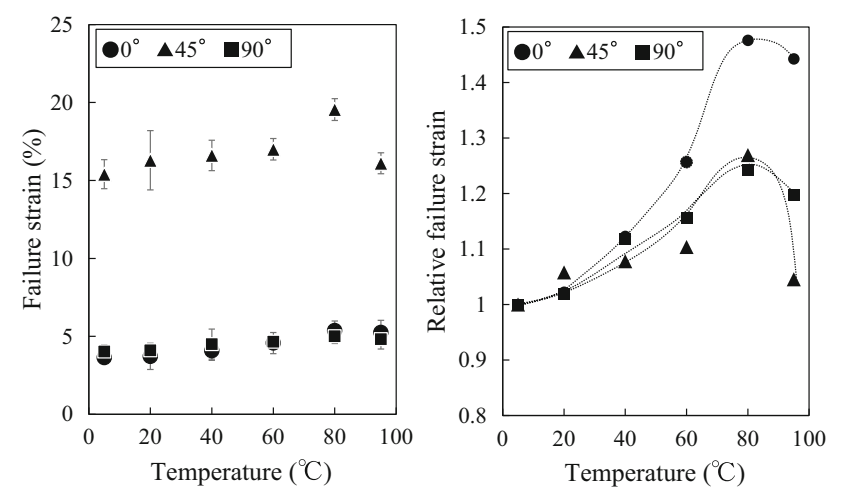

Fig. 2 Failure strains and relative failure strains measured at each temperature. Relative failure strain is relative to the failure strain measured at $5{ }^{\circ} \mathrm{C}$ in each annual ring inclination. Symbols mean the average value and error bars mean $95 \%$ confidence interval

range between 80 and $95{ }^{\circ} \mathrm{C}$ is the temperature range where the weak parts as the starting point of fracture are changed, and where the fractures tend to occur because weak parts are increased in the specimens. Therefore, failure strains decreased largely, as shown in Fig. 2.
The appearance ratios of various fractures and photographs of broken specimen with the annual ring inclination of $90^{\circ}$ are shown in Fig. 5. The photographs show that fractures tended to occur in the intercellular layers along the annual rings for the specimens with the inclination of $90^{\circ}$. Focusing on the appearance ratios of fractures, the fractures along the annual rings were less frequent in their ratio as low as about $20 \%$ at $20{ }^{\circ} \mathrm{C}$, whereas the ratios were more or less $50 \%$ at $80{ }^{\circ} \mathrm{C}$ or higher. Thus, the fractures along the annual rings should tend to occur with increase of temperature. Focusing on the percentage of breaking length of the ray tissues in horizontal direction, it decreased at $80^{\circ} \mathrm{C}$ as compared with $20^{\circ} \mathrm{C}$, and few fractures were found along the ray tissues at $95^{\circ} \mathrm{C}$. From the results above, in the specimens with the inclination of $90^{\circ}$, fractures tended to occur in the intercellular layers along the ray tissues at $20^{\circ} \mathrm{C}$, whereas the intercellular layers between early wood and late wood also became weak with increase in the temperature. Therefore, annual ring boundaries became the weakest in the specimens at $95{ }^{\circ} \mathrm{C}$, and failure strains were reduced at $95{ }^{\circ} \mathrm{C}$ as shown in Fig. 2.

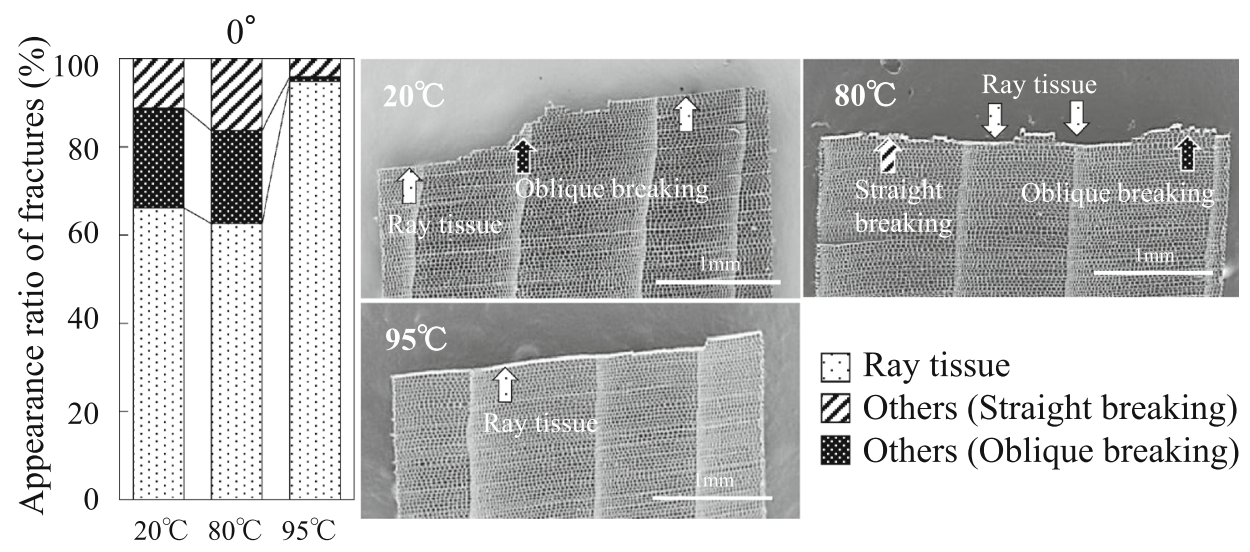

Fig. 3 Appearance ratio of fractures along each tissue and photographs of broken specimen with the annual ring inclination of $0^{\circ}$

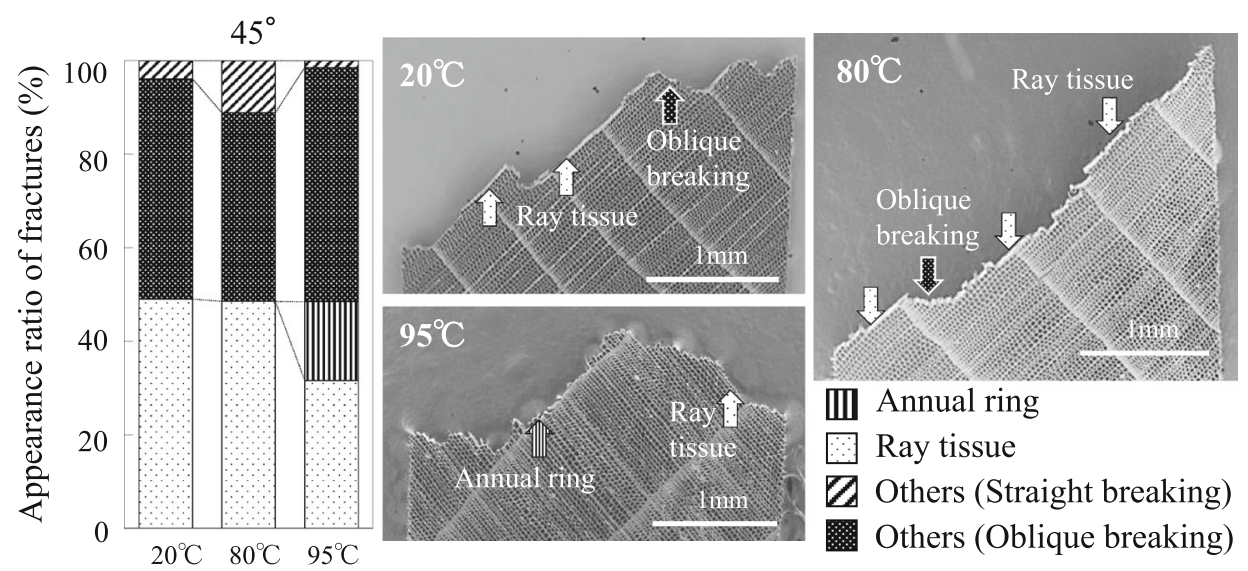

Fig. 4 Appearance ratio of fractures along each tissue and photographs of broken specimen with the annual ring inclination of $45^{\circ}$ 


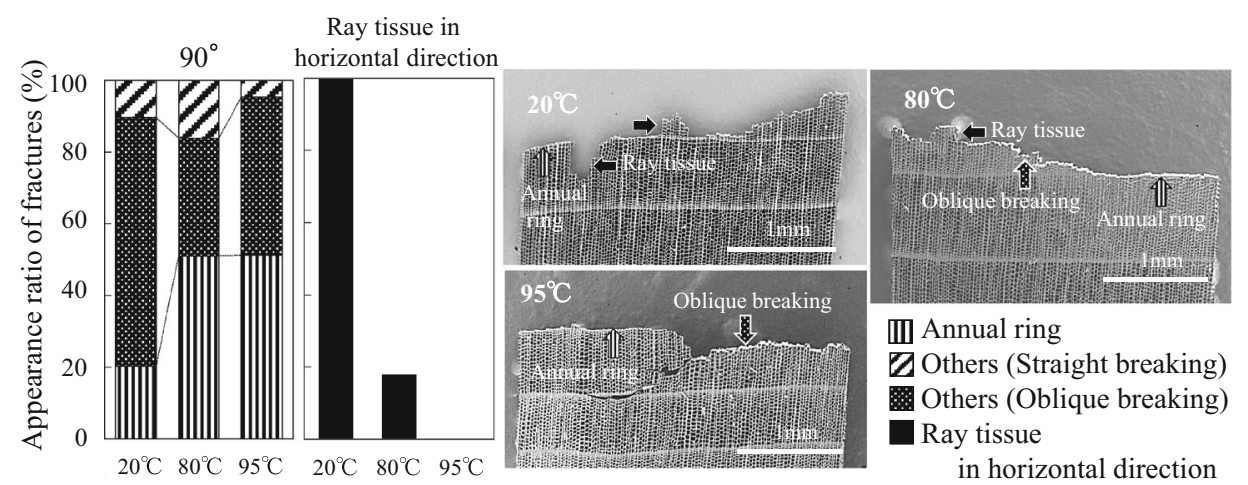

Fig. 5 Appearance ratio of fractures along each tissue and photographs of broken specimen with the annual ring inclination of $90^{\circ}$

It was suggested from these results that the weakest parts as starting points of fractures changed for all of the specimens in the temperature range between 80 and $95{ }^{\circ} \mathrm{C}$. Therefore, the weak parts for fractures were increased as the temperature rose, as the result failure strains decreased.

\section{Changes in the rheological properties of wood with increase in temperature}

Then the thermal softening of wood was assessed from the elastic modulus measured in various temperatures to discuss the effect of softening on increase of failure strain. To obtain the information about decrease in $E$ at the tensile breaking in this study, $E$ was measured at the same loading rate of the tensile breaking test. On the other hand, the IE was also measured to have the information about the pure elastic modulus that does not include the creep deformation in the loading process as far as possible. The results obtained are shown in Fig. 6. $E$ and IE had larger values in the order of the annual ring inclination of $90^{\circ}, 0^{\circ}, 45^{\circ}$, and the values tended to decrease with increase in temperature. IE had larger value than $E$ at any temperature, and the difference between their values was larger in the higher temperature especially for the specimens with the annual ring inclination of $90^{\circ}$ and $0^{\circ}$. The reason why $E$ is smaller than IE at the higher temperatures is considered to be as follows:

The load speed for measuring $E$ was much slower than that in IE, therefore, larger creep amount of wood is included for $E$ than that for IE. Because the creep amount during the deformation is greater at the high temperature side where the wood is softened [18], the difference between $E$ and IE values was shown prominently at higher temperatures.

Elastic compliance which means the ease of elastic deformation was determined from the values for the elastic modulus. Elastic compliance was the largest in the specimens with the annual ring inclination of $45^{\circ}$ and followed by those with the annual ring inclination of $0^{\circ}$ and $90^{\circ}$ as shown in Fig. 6. In all of the specimens, the IE compliance and the $E$ compliance increased with increase in temperature, and in which the $E$ compliance obviously indicated the larger value than the IE compliance at higher temperatures.

From the results above, it was predicted that the tensile failure strains measured in this study were affected by creep deformation. Therefore, creep of each specimen was measured at each temperature and calculated the creep compliance $(J(30))$ as an index of fluidity to clarify the effect of fluidity contained at the time of deformation. Figure 7 shows the relationship between $J(30)$ and the temperature. As common to all of the specimens, the tendency was observed that $J(30)$ increased with increase from about $40{ }^{\circ} \mathrm{C}$ where the wood started to be softened [18]. The largest $J(30)$ was shown in the specimens with the annual ring inclination of $45^{\circ}$ at any temperature. $J(30)$ of the annual ring inclination of $0^{\circ}$ and $90^{\circ}$ was comparable up to around $60{ }^{\circ} \mathrm{C}$, whereas $J(30)$ of the annual ring inclination of $0^{\circ}$ was larger than those of $90^{\circ}$ at higher temperatures. The reason why $J(30)$ has different characteristics among annual ring inclinations can be assumed as follows:

In the specimens with the angle of $0^{\circ}$, late wood layers are arranged in parallel against the tensile direction, and creep amount should depend on the amount of fluidity caused in wood substance. Therefore, $J(30)$ increased as the temperature increased because the fluidity of late wood layers aligned in the tensile direction increased the above around $40{ }^{\circ} \mathrm{C}$ which was the temperature range where Hinoki started to be softened [15].

On the other hand, in the specimens with the annual ring inclination of $90^{\circ}$, late wood layer and early wood layer are arranged alternately against the tensile direction. $J(30)$ is determined from the sum of the creep amount of late wood with thick cell wall and early wood with thin cell wall. Therefore, in the specimens with the annual ring inclination of $90^{\circ}, J(30)$ was smaller than that of $0^{\circ}$ which late wood layers arranged in a row against the tensile direction. 

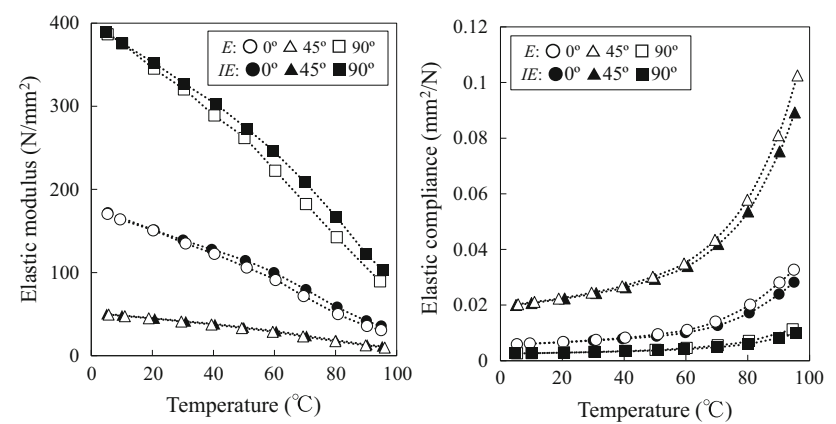

Fig. 6 Elastic modulus and elastic compliance measured at each temperature. Open symbols are elastic modulus and closed symbols are instantaneous elastic modulus

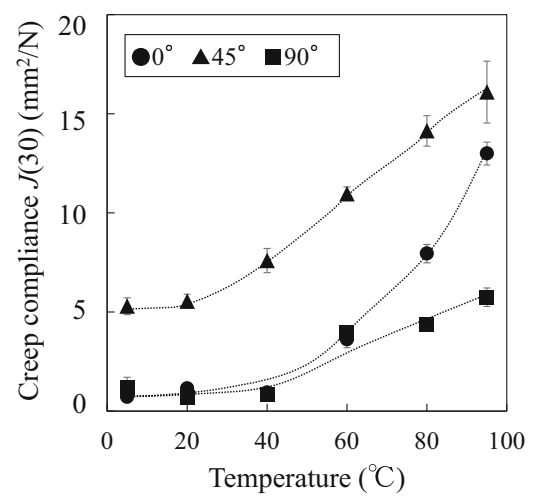

Fig. 7 Relationship between creep compliance and temperature. Symbols mean the average values and error bars mean $95 \%$ confidence interval

In the specimens with the annual ring inclination of $90^{\circ}$, ray tissues are also arranged in parallel to the tensile direction, therefore, the increase in $J(30)$ was also disturbed by those tissues.

In the specimens with the inclination of $45^{\circ}$ with the largest $J(30)$, the shape of cell is deformed roughly from a square shape to a diamond shape against the tensile load [1, 19]. Furthermore, ray tissue which disturbs the deformation of cells is oriented to the direction with the inclination of $45^{\circ}$ to the tensile direction. Thus, these tissues should effect on $J(30)$ complicatedly with increase of tensile deformation. However, too large deformation did not occur, because the stress applied in this experiment was $25 \%$ of the strength and the tensile failure strain was approximately $3 \%$. Therefore, the larger $J(30)$ in the specimens with the inclination of $45^{\circ}$ are due to not those tissues, but the deformation of cells, and the cell deformation should be accelerated with increase in temperature.

From these results, the effects of creep deformation, that is, fluidity are included in the tensile deformation process of wood, and the fluidity has different characteristics dependent upon the tissue structure and the load direction.
The relationship between the rheological properties of wood and failure strains

To examine the effects of changes in rheological properties of wood on failure strains, the relationship between relative values of the $E$ compliance and those of failure strains is shown in Fig. 8. The elastic modulus measured at the same loading rate was used as the index of the degree of softening with increase in temperature. Except of the temperature range in which failure strains decreased, linear relationship was found between the relative value of the $E$ compliance and that of failure strains. The relationship between the relative failure strains and the relative $E$ compliance was also clearly shown in the specimens with the inclination of $0^{\circ}$ which the increase ratio of failure strain was particularly large. The reasons of these results were considered as follows:

Deformation mode of the specimen with the inclination of $0^{\circ}$ is hardly affected by the ray tissues which disturb the deformation. Therefore, increase in failure strains was affected primarily by the softening, thus relationship was observed clearly between the relative failure strain and the relative $E$ compliance. From the results described above, effects of softening of wood is important for increasing failure strains up to the temperature range in which the fracture mechanism changes. Moreover, effect of softening on failure strains was most clearly found in annual ring inclination of $0^{\circ}$ which the ray tissues and deformation of cells did not affect the deformation of the specimens.

On the other hand, the effects of creep deformation of specimens with each annual ring inclination on failure strain were examined, because the creep deformation caused in the loading process is also included in the amount of deformation until the wood fracture. The relationship between the relative values of $J(30)$ and relative failure strains is shown in Fig. 9. In the specimen with the annual

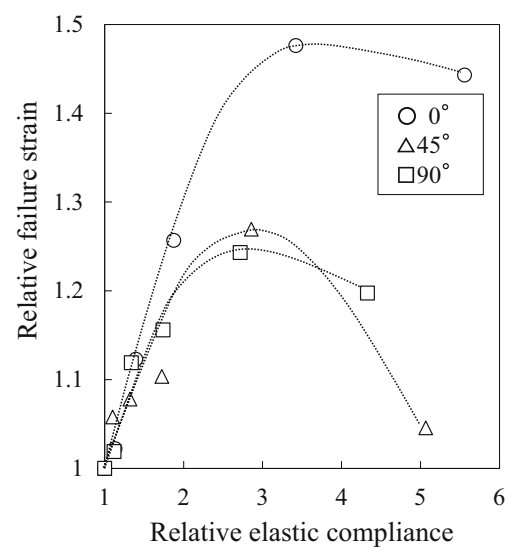

Fig. 8 Relative failure strain and relative elastic compliance are those measured at $5{ }^{\circ} \mathrm{C}$ in each annual ring inclination 


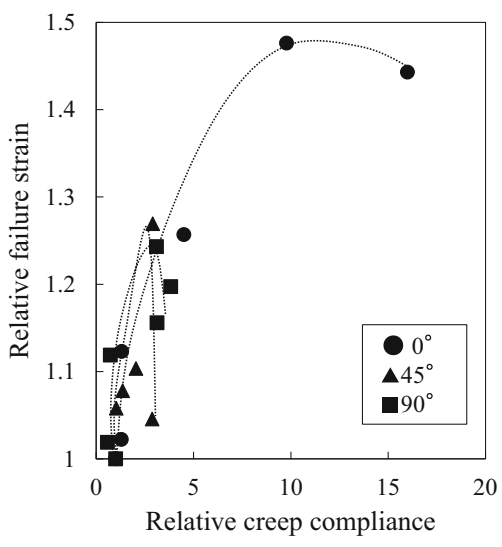

Fig. 9 Relative failure strain and relative creep compliance are those measured at $5{ }^{\circ} \mathrm{C}$ in each annual ring inclination

ring inclination of $0^{\circ}$ and $45^{\circ}$, roughly linear relationship was found between the increase ratios of $J(30)$ and failure strains up to the temperature range where failure strains decreased. However, that relationship was not clearer than that of the elastic compliance, and the relationship was not found in the specimen with the inclination of $90^{\circ}$. In other words, the creep deformation occurred before fracture did not significantly affect the increase in failure strain.

\section{Conclusions}

For the purpose of elucidating the effect of rheological property of wood on lateral tensile fracture, failure strain, elastic modulus, and creep at various temperature conditions were measured. And, relationship between the degree of softening or fluidity and lateral tensile failure strain was examined. To discuss the fracture mechanism from the results of the failure strains, fracture surfaces were observed and appearance ratio of breaking was calculated. The results obtained are as follows:

1. The range between 80 and $95{ }^{\circ} \mathrm{C}$ is the temperature range where the weak parts as the starting point of fracture are changed, and where the fractures tend to occur because weak parts are increased in the specimens.

2. The effects of softening of wood are important for increasing failure strains up to the temperature range in which the fracture mechanism changes. Moreover, effect of softening on failure strains was most clearly found in annual ring inclination of $0^{\circ}$ which the ray tissues and deformation of cells did not affect the deformation of the specimens.

3. Creep deformation, that is, fluidity was included in the wood deformation process, and the fluidity had different characteristics dependent on the anatomical characteristics. It also became clear that the creep deformation measured in the load range of this study did not affect the increase in failure strain significantly.

\section{References}

1. Miyoshi Y, Kojiro K, Furuta Y (2014) Deformation properties of wood in lateral tension effect of tensile direction to the annual rings, moisture, and temperature on lateral tensile deformation of Hinoki (Chamaecyparis obtusa) (in Japanese). Mokuzai Gakkaishi 60:241-248

2. Miyoshi Y, Kojiro K, Furuta Y (2015) Effect of anatomy and thermal-softening properties on lateral tensile deformation properties of various wood species (in Japanese). J Soc Mat Sci Jpn 64:356-361

3. Miyoshi Y, Kiryu T, Kojiro K, Furuta Y (2015) Effects of drying and/or quenching histories on lateral tensile deformation properties of water-swollen wood. J Wood Sci 61:525-528

4. Sato Y, Fushitani M, Kubo T (1987) Effect of structure factors on the softening of wood due to heat and water (in Japanese). Mokuzai Gakkaishi 33:921-928

5. Sato Y, Fushitani M, Kubo T (1990) Relationships between structural factors and ratios of change in bending deformation properties of woods due to heat and water (in Japanese). Mokuzai Gakkaishi 36:709-716

6. Keunecke D, Stanzl-Tschegg S, Niemz P (2007) Fracture characterisation of yew (Taxus baccata L.) and spruce (Picea abies [L.] Karst.) in the radial-tangential and tangential-radial crack propagation system by a micro wedge splitting test. Holzforschung 61:582-588

7. Köhler L, Spatz H-CH (2002) Micromechanics of plant tissues beyond the linear-elastic range. Planta 215:22-40

8. Takahashi A (1966) Strain determination of wood by using photo elastic coating technique. Effect of grain angle (longitudinal direction) to tensile strength and to strain distribution on wooden member with a hole (in Japanese). Mokuzai Gakkaishi 12:160-166

9. Eric LE (1953) Properties of beech in tension perpendicular to the grain and their relation to drying. J For Prod Res Soc 3:202-209

10. Fukuyama M, Takemura $T$ (1962) The effects of temperature on tensile properties perpendicular to grain of wood (in Japanese). Mokuzai Gakkaishi 8:185-191

11. Lanvermann C, Hass P, Wittel FK, Niemz P (2014) Mechanical properties of Norway spruce: intra-ring variation and generic behavior of earlywood and latewood until failure. Bioresources 9:105-119

12. Navi P, Stanzl-Tschegg S (2009) Micromechanics of creep and relaxation of wood. Holzforschung 63:186-195

13. Furuta Y, Yano H, Kajita H (1995) Thermal-softening properties of water-swollen wood. The effect of drying history (in Japanese). Mokuzai Gakkaishi 41:718-721

14. Furuta Y, Makinaga M, Yano H, Kajita H (1997) Thermal-softening properties of water swollen-wood. Anisotropic characteristics of thermal-softening properties (in Japanese). Mokuzai Gakkaishi 43:16-23

15. Furuta Y, Norimoto M, Yano H (1998) Thermal-softening properties of water swollen-wood. The effects of drying and heating histories (in Japanese). Mokuzai Gakkaishi 44:82-88

16. Suzuki S, Okuyama T, Terazawa S (1979) Effect of temperature on orthotropic properties of wood. Proportion of transwall failure. Mokuzai Gakkaishi 25:177-183 
17. Iida I (1989) Changes of elastic and strength properties in the direction perpendicular to the grain by moisture content change and by heating in water (in Japanese). Mokuzai Gakkaishi $35: 875-881$

18. Sawabe O (1974) Studies on the thermal softening of wood. Effects of the temperature on the bending creep of dry Hinoki wood. Mokuzai Gakkaishi 20:517-522
19. Kanaya N, Yamada T (1967) Wood by transverse tensile tests (in Japanese). Wood Res 41:47-62 